\title{
Regulation of Matrix Metalloproteinases-2 and -9 Gene Expression in Cultured Human Fetal Membrane Cells by Influenza Virus Infection
}

\author{
Noboru Uchide, ${ }^{*}, a, b$ Kyoko Obatake, ${ }^{a}$ Rie Yamada, ${ }^{a}$ Hidetaka Sadanari, ${ }^{a}$ Keiko Matsubara, ${ }^{a}$ \\ Tsugiya Murayama, ${ }^{a}$ and Kunio Ohyama ${ }^{b}$ \\ ${ }^{a}$ Department of Clinical Pharmacy, Faculty of Pharmaceutical Sciences, Hokuriku University; Ho-3 Kanagawa- \\ machi, Kanazawa, Ishikawa 920-1181, Japan: and ${ }^{b}$ Department of Clinical Molecular Genetics, School of Pharmacy, \\ Tokyo University of Pharmacy and Life Sciences; 1432-1 Horinouchi, Hachioji, Tokyo 192-0392, Japan. \\ Received January 28, 2016; accepted September 5, 2016
}

In order to understand a possible etiology of adverse pregnancy outcomes associated with intrauterine influenza virus infection, we examined the effect of influenza virus infection on gene expression of matrix metalloproteinases (MMPs) in cultured amnion epithelial, amnion mesenchymal and chorion trophoblast cells prepared from human fetal membrane tissues by gelatin zymography, Western blotting and reverse transcriptase-PCR. The cells were infected with influenza A (H1N1) virus. The levels of pro-MMP-9 activity in culture supernatants of three types of cells were increased during the period of $24-48 \mathrm{~h}$ after the virus infection as compared to those of mock infection. Chorion trophoblast cells spontaneously released a much greater level of pro-MMP-2 activity than amnion epithelial and amnion mesenchymal cells. The cleavage of pro-MMP-2 into an active intermediate form was enhanced in chorion trophoblast cells by the virus infection. The activity levels of MMP-2 and MMP-9 in culture supernatants were consistent with their protein levels. The virus infection induced the mRNA expression of MMP-9, but not MMP-2, in three types of cells. These results suggest that influenza virus infection induces the gene expression of MMP-9 and the cleavage of pro-MMP-2 into an active intermediate form in human fetal membrane cells, resulting in weakening of the membranes through extracellular matrix degradation. Therefore, it is possible that the regulation of MMPs gene expression in fetal membrane cells by influenza virus infection is implicated in a part of the etiology of adverse pregnancy outcomes associated with intrauterine infection with the virus.

Key words matrix metalloproteinase; fetal membrane; influenza virus; placenta; pregnancy

Human fetal membranes, which surround the amniotic cavity and enclose the fetus, are composed of several types of cells and extracellular matrix fibers ${ }^{1-3)}$ (Fig. 1). The amnion layer is composed of epithelial cells, which sit upon a basement membrane including type IV collagen, and mesenchymal cells, while the chorion layer is composed of trophoblast cells and mesenchymal cells. During the normal parturition process at term, these membranes rupture after the onset of uterine contractions. When ruptures take place prior to term, this leads to a preterm birth, which is a major risk factor for neonatal morbidity and mortality. The mechanisms involved with both the preterm and term parturition in humans have been widely shown and accepted to be associated with inflammation in the fetal membranes. ${ }^{4}$

The worldwide study of the 2009 flu pandemic caused by a novel influenza A (H1N1) virus has clearly demonstrated that pregnant women confirmed to be infected with the pandemic strain of A (H1N1) pdm09 virus using PCR analysis were at an increased risk of adverse pregnancy outcomes. These adverse outcomes included premature delivery, spontaneous abortion and fetal distress. ${ }^{5,6}$ Although influenza viruses mainly attack the upper respiratory tracts, the viruses have been rarely isolated from or detected in human placentas obtained from patients infected with human influenza A (H1N1) virus, ${ }^{7)}$ (H3N2) virus, ${ }^{8)}$ influenza B virus, ${ }^{9)}$ or the avian influenza A (H5N1) virus. ${ }^{10)}$ Intranasal inoculation of pregnant mice with the $\mathrm{H} 5 \mathrm{~N} 1$ virus has been shown to lead to transplacental transmission of the virus, which subsequently resulted in abortion and preterm delivery. ${ }^{11)}$ Consequently, it can be considered that a direct effect of influenza virus infection on gestational tissues may be implicated in the etiology of adverse pregnancy outcomes. Interestingly, we have reported that influenza virus infection induced apoptosis and the gene expression of interleukin (IL)-6, tumor necrosis factor (TNF)- $\alpha$ and interferon (IFN)- $\beta$ in cultured human fetal membrane chorion trophoblast cells. ${ }^{12-14)}$ However, even though the virus proliferated in cultured amnion epithelial cells, it should be noted that we did not observe the above phenomena in these cells. ${ }^{12-14)}$ Overall, these findings suggest that the induction of apoptosis and gene expression of pro-inflammatory cytokines in chorion trophoblast cells may have a possible role in the etiology of adverse pregnancy outcomes that are associated with an intrauterine infection caused by an influenza virus. $^{5,15)}$

The main etiological factor responsible for the development of both premature rupture of the membranes (PROM) and preterm labor has been reported to be an intrauterine bacterial infection., ${ }^{3,4,16)}$ Although the mechanisms responsible for the PROM due to bacterial infection are not yet elucidated definitely, a premature activation of apoptotic cell death and extracellular matrix degradation by matrix metalloproteinases (MMPs) in the membranes appears to be implicated. ${ }^{3)}$ Both term labor and PROM have been found to be associated with increased levels of MMP-9 and reduced levels of tissue inhibitor of MMP-1 (TIMP-1) in the amniotic fluid. ${ }^{17)}$ A comparison of the levels of MMP-2 and MMP-9 in cultured fetal membrane tissues between non-laboring women to those with proven intra-amniotic infection, found that MMP-2 was present in 


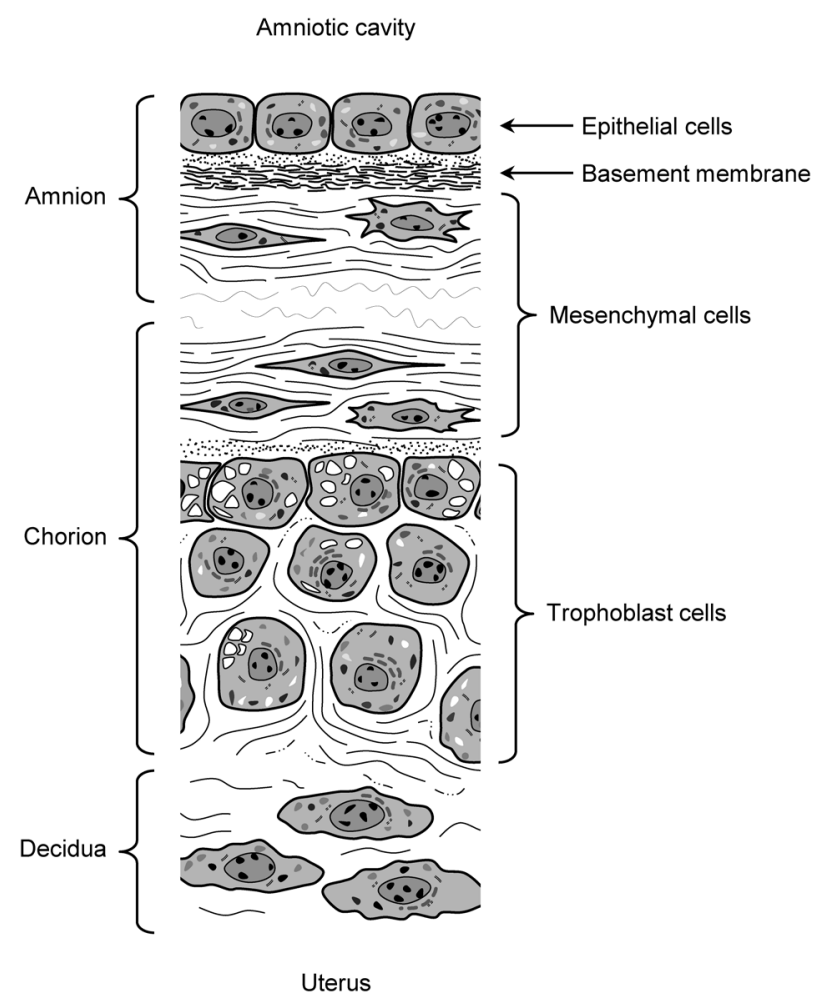

Fig. 1. Schematic Diagram of the Human Fetal Membranes

Human fetal membranes are composed of the amnion and the chorion layers. The amnion layer is made up of amnion epithelial and amnion mesenchymal cells, while chorion is made up of chorion trophoblast and mesenchymal cells. This panel has been reproduced from our previously published study in the Mediators of Inflammation $^{9)}$ with permission of the publishers of the journal.

both groups while MMP-9 was not present in non-laboring women but appeared in those with infections. ${ }^{18)}$ It seems that MMP-9 plays a crucial role in both physiological and pathological processes leading to rupture of the membranes, and MMP-2 has a fundamental role in tissue remodeling, including placental growth during pregnancy. ${ }^{19-21)}$ Particularly, it has been postulated that pro-inflammatory cytokines, such as IL- $1 \beta$, IL-6 and TNF- $\alpha$, may have a pivotal role in the etiology of the bacterial infection-associated preterm PROM. This hypothesis is based on the fact that these cytokines have been shown to be able to activate pro-apoptotic proteases (i.e., caspases) and MMP-9 production in isolated fetal membrane tissues, thereby leading to a physical weakening of the tissues. $^{22-24)}$

Influenza virus infection has been shown to induce the gene expression of MMP-9 in certain types of epithelial cells, such as Vero cells and Madin-Darby canine kidney (MDCK) cells. $^{25}$ ) The induction of MMP-9 gene expression appears to be related to the destruction of various organs infected with influenza virus. ${ }^{26}$ ) Pro-MMP-2 undergoes stepwise activation. ${ }^{27)}$ Membrane type (MT) 1-MMP leads to the cleavage of pro-MMP-2, generating an active intermediate form (64-68 kDa). Autocatalysis of the intermediate form results in the fully activated form of MMP-2 (ca. $62 \mathrm{kDa}$ ). TIMPs form 1:1 stoichiometric complexes with MMP and inhibit their proteolytic activity. TIMP-1 binds to an active form of MMP-9, and TIMP-2 binds to pro-form and active forms of MMP-2. Coordinated activities of MMPs and TIMPs are essential to the process of extracellular matrix remodeling. However, it has remained unclear whether influenza virus infection regulates the gene expression of MMPs in human gestational tissues or not. Therefore, we further examined the effect of influenza virus infections on the gene expression of MMP-2, MMP-9, MT1MMP, TIMP-1 and TIMP-2 in cultured human fetal membrane cells, and then attempted to elucidate the possible etiology of the adverse pregnancy outcomes that have been shown to be associated with influenza virus infection.

\section{MATERIALS AND METHODS}

Preparation of Primary Cultured Cells All of the human fetal membrane tissues were collected by elective cesarean section procedures that were performed during the month of the normal parturition. The Institutional Review Board Committee of Tokyo University of Pharmacy and Life Sciences approved both the study and the use of human tissues (receipt number 09-06). After obtaining informed consent from patients at the time of surgery, primary cultured chorion trophoblast, amnion epithelial and amnion mesenchymal cells were collected and prepared from the separated amniochorion tissues, as per previously described studies. ${ }^{14,28)}$ The approximate cell densities of the chorion trophoblast, amnion epithelial and amnion mesenchymal cells were $8 \times 10^{4}, 20 \times 10^{4}$ and $8 \times 10^{4}$ cells $/ \mathrm{cm}^{2}$, respectively.

Immunohistochemical Analysis It has been demonstrated that cytokeratin 7 is a marker for epithelial cells and trophoblast cells, ${ }^{29)}$ vimentin is a maker for trophoblast and mesenchymal cells such as fibroblast cells, ${ }^{30,31)}$ and $\alpha$-smooth muscle actin is a marker for myofibroblast cells. ${ }^{32)}$ In order to identify the cell types in the preparations of cultured cells, immunohistochemical staining was performed with mouse monoclonal antibodies against cytoskeletal filaments, such as human cytokeratin 7, vimentin and $\alpha$-smooth muscle actin, and Dako ENVISION kit HRP/DAB (Dako North America Inc., CA, U.S.A.) according to the manufacturer's protocol. Non-immunized mouse immunoglobulin G (IgG) (Dako North America Inc.) was used as a negative control antibody. Cells were counterstained with hematoxylin solution (Merck, Darmstadt, Germany) and enclosed with Entellan neu (Merck). Cells were observed under a microscope.

Viruses and Infection Embryonal chicken eggs were used for the propagation of the influenza A (H1N1) virus $\left.(\mathrm{PR} / 8 / 34) .{ }^{12}\right)$ The number of infectious virus particles within the chorioallantoic fluid was $4 \times 10^{6}$ plaque-forming units (p.f.u.)/mL. The influenza virus particles at $0.8,2$ and 2 multiplicities of infection (m.o.i.), respectively, were used to infect the confluent monolayers of the amnion epithelial, amnion mesenchymal and chorion trophoblast cells, as has been previously described. ${ }^{12)}$ We also prepared confluent monolayers of cells in the absence of viruses for use as the mock-infected control cells. Using $0.2 \mathrm{~mL} / \mathrm{cm}^{2}$ of macrophage serum-free medium (Invitrogen, MD, U.S.A.), all of the cells were incubated for the desired experimental periods in a $\mathrm{CO}_{2}$ incubator.

Gelatin Zymography Cells were incubated with macrophage serum-free medium until $48 \mathrm{~h}$ after the virus infection with changing fresh medium at $24 \mathrm{~h}$. The culture supernatants incubated during the periods of $0-24 \mathrm{~h}$ and $24-48 \mathrm{~h}$ after infection were collected by centrifugation at $600 \times \boldsymbol{g}$ for $5 \mathrm{~min}$ at $4^{\circ} \mathrm{C}$ and stored at $-80^{\circ} \mathrm{C}$ until use. The culture supernatants were thawed and mixed with an equal volume of sample buffer (125 mm Tris- $\mathrm{HCl}$ ( $\mathrm{pH}$ 6.8), 4\% sodium dodecyl sulfate 
Table 1. PCR Primers and Optimal Cycles

\begin{tabular}{|c|c|c|c|}
\hline Target genes & Sites & DNA sequences & Optimal PCR cycles \\
\hline \multirow[t]{2}{*}{ MMP-2 } & $\mathrm{S}$ & 5'-ACC TAC ACC AAG AAC TTC CG-3' & 24 \\
\hline & AS & 5'-TTG GTT CTC CAG CTT CAG GT-3' & \\
\hline \multirow[t]{2}{*}{ MMP-9 } & $\mathrm{S}$ & 5'-TCC CTG GAG ACC TGA GAA CC-3' & 27 \\
\hline & AS & 5'-CGG CAA GTC TTC CGA GTA GTT-3' & \\
\hline \multirow[t]{2}{*}{ MT1-MMP } & $\mathrm{S}$ & 5'-GCA GAA GTT TTA CGG CTT GCA-3' & 24 \\
\hline & AS & 5'-TCG AAC ATT GGC CTT GAT CTC-3' & \\
\hline \multirow[t]{2}{*}{ TIMP-1 } & $\mathrm{S}$ & 5'-CCG CAG CGA GGA GTT TCT C-3' & 27 \\
\hline & AS & 5'-GAG CTA AGC TCA GGC TGT TCC A-3' & \\
\hline \multirow[t]{2}{*}{ TIMP-2 } & $\mathrm{S}$ & 5'-CGA CAT TTA TGG CAA CCC TAT CA-3' & 27 \\
\hline & AS & 5'-GCC GTG TAG ATA AAC TCT ATA TCC-3' & \\
\hline \multirow[t]{2}{*}{$\beta$-Actin } & $\mathrm{S}$ & 5'-CCT TCC TGG GCA TGG AGT CCT G-3' & 21 \\
\hline & AS & 5'-GGA GCA ATG ATC TTG ATC TTC-3' & \\
\hline \multirow[t]{2}{*}{ G3PDH } & $\mathrm{S}$ & 5'-TGA AGG TCG GAG TCA ACG GAT TTG GT-3' & 21 \\
\hline & AS & 5'-CAT GTG GGC CAT GAG GTC CAC CAC-3' & \\
\hline
\end{tabular}

Abbreviations: AS, antisense; G3PDH, glucerol-3-phosphate dehydrogenase; MMP, matrix metalloproteinase; MT1-MMP, membrane type 1-matrix metalloproteinase; S, sense; TIMP, tissue inhibitor of matrix metalloproteinase.

(SDS), 20\% glycerol, $0.01 \%$ bromophenol blue). The activities of gelatinases in culture supernatants were detected by gelatin zymography as described. ${ }^{33)}$ Briefly, an aliquot $(5 \mu \mathrm{L})$ of the culture supernatants was subjected to SDS-polyacrylamide gel electrophoresis (PAGE) using 10\% acrylamide gel containing $0.6 \mathrm{mg} / \mathrm{mL}$ of gelatin (Difco, MI, U.S.A.). After electrophoretic separation, the gels were washed twice for $30 \mathrm{~min}$ with washing buffer (50mM Tris- $\mathrm{HCl}(\mathrm{pH} 7.5), 5 \mathrm{mM} \mathrm{CaCl}_{2}, 1 \mu \mathrm{M}$ $\mathrm{ZnCl}_{2}, 2.5 \%$ Triton $\left.\mathrm{X}-100\right)$ at room temperature and incubated in reaction buffer ( $50 \mathrm{~mm}$ Tris- $\mathrm{HCl}(\mathrm{pH} 7.5), 5 \mathrm{~mm} \mathrm{CaCl}_{2}, 1 \mu \mathrm{M}$ $\mathrm{ZnCl}_{2}$ ) for $16 \mathrm{~h}$ at $37^{\circ} \mathrm{C}$. The gels were stained with $0.25 \%$ Coomassie Brilliant Blue R-250 in 50\% methanol and $10 \%$ acetic acid. After washing away the excess dye with a solution ( $25 \%$ methanol and $7 \%$ acetic acid), the gelatinolytic activity was appeared as clear bands on a blue background. The gelatinolytic activities were analyzed with NIH imageJ 1.440 . The gelatinases were identified as pro-MMP-2 $(72 \mathrm{kDa})$, cleaved form of MMP-2 (68 kDa) and pro-MMP-9 (92 kDa) according to the relative molecular masses determined by comparison with SDS-PAGE molecular weight protein markers (Bio-Rad CA, U.S.A.) in the adjacent lane.

Western Blot Analysis As described above, the culture supernatants incubated during the periods of $0-24 \mathrm{~h}$ and $24-48 \mathrm{~h}$ after infection were collected. Briefly, an aliquot $(5 \mu \mathrm{L})$ of the culture supernatants was subjected to SDS-PAGE using $10 \%$ acrylamide gels and transferred to nitrocellulose membranes according to standard procedures as described previously. ${ }^{14)}$ In order to detect MMP-2 and MMP-9 proteins on the membranes, we used rabbit polyclonal anti-MMP-2 and antiMMP-9 antibodies (Cell Signaling Technology, MA, U.S.A.), respectively, along with horseradish peroxidase-labeled donkey anti-rabbit IgG antibody and $\mathrm{ECL}^{\mathrm{TM}}$ prime Western blotting detection reagents (GE Healthcare Japan, Tokyo, Japan). Chemiluminescence was detected with a lumino image analyzer, LAS-1000plus (FUJIFILM, Tokyo, Japan), and quantitated with the software Image Gauge (FUJIFILM).

Reverse Transcriptase (RT)-PCR Cells were incubated with macrophage serum-free medium for $48 \mathrm{~h}$ after the virus infection. RT-PCR was carried out as described previously. ${ }^{13)}$ PCR primers for MMP-2, MMP-9, MT1-MMP, TIMP-1, TIMP-2, $\beta$-actin, glycerol-3-phosphate dehydrogenase
(G3PDH) were referred to the published DNA sequences as listed in Table $1 .{ }^{13,34-36)}$ They were custom-made by SigmaGenosis (Tokyo, Japan). PCR amplification was performed with optimal numbers of PCR cycle as listed in Table 1. Each cycle consisted of denaturation at $94^{\circ} \mathrm{C}$ for $45 \mathrm{~s}$, annealing at $60^{\circ} \mathrm{C}$ for $45 \mathrm{~s}$ and extension at $72^{\circ} \mathrm{C}$ for $2 \mathrm{~min}$, followed by final extension at $72^{\circ} \mathrm{C}$ for $7 \mathrm{~min}$. Reaction mixtures $(5 \mu \mathrm{L})$ after PCR were resolved on 2\% agarose gels by electrophoresis. After staining with ethidium bromide, gel images on UV trans-illuminator were obtained.

Statistical Analysis Statistical analysis was performed using the Student $t$-test method. A $p$ value less than 0.05 was considered significant.

\section{RESULTS}

Expression of Cytoskeletal Filaments in Preparations of Cultured Human Fetal Membrane Cells In order to elucidate phenotypes of cultured cells, the expression of cytoskeletal filaments in cells was analyzed by immunohistochemical techniques (Fig. 2). Cultured amnion epithelial cells consisted of a large number of epithelial-like cells, which were strongly positive for cytokeratin 7 and weakly positive for vimentin but negative for $\alpha$-smooth muscle actin. A small number of fibroblast-like cells, strongly positive for both cytokeratin 7 and vimentin, and myofibroblast-like cells, positive for $\alpha$-smooth muscle actin, were detected.

Cultured amnion mesenchymal cells consisted of a large number of epithelial-like cells, which were weakly positive for both cytokeratin 7 and vimentin but negative for $\alpha$-smooth muscle actin. A small number of fibroblast-like cells, strongly positive for both cytokeratin 7 and vimentin, and myofibroblast-like cells, positive for $\alpha$-smooth muscle actin, were detected, both of which constructed a reticular-like structure.

Cultured chorion trophoblast cells consisted of a large number of fibroblast-like cells, which were strongly positive for both cytokeratin 7 and vimentin but negative for $\alpha$-smooth muscle actin. A small number of myofibroblast-like cells, positive for $\alpha$-smooth muscle actin, were detected.

In brief, although there were differences in the levels of expression, almost all cells in all three cultures were positive 

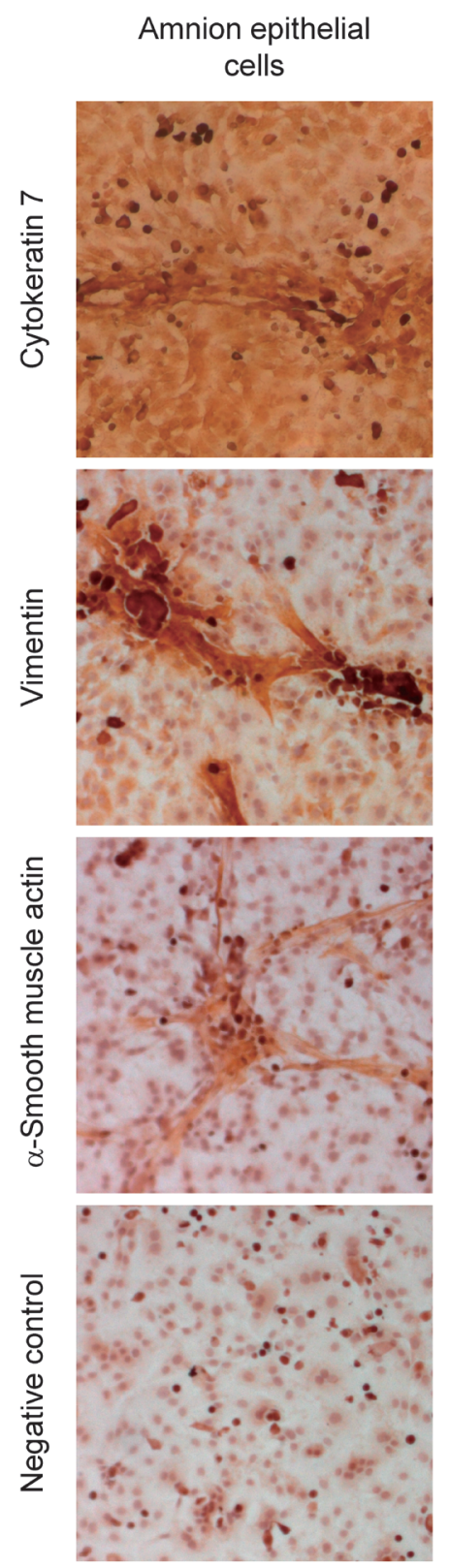

Amnion mesenchymal cells
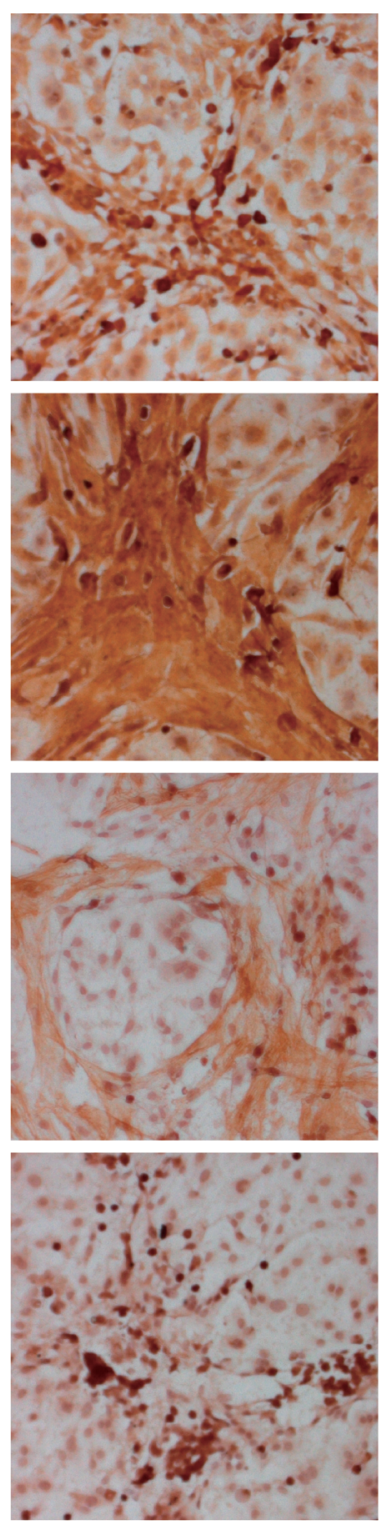

Chorion trophoblast cells
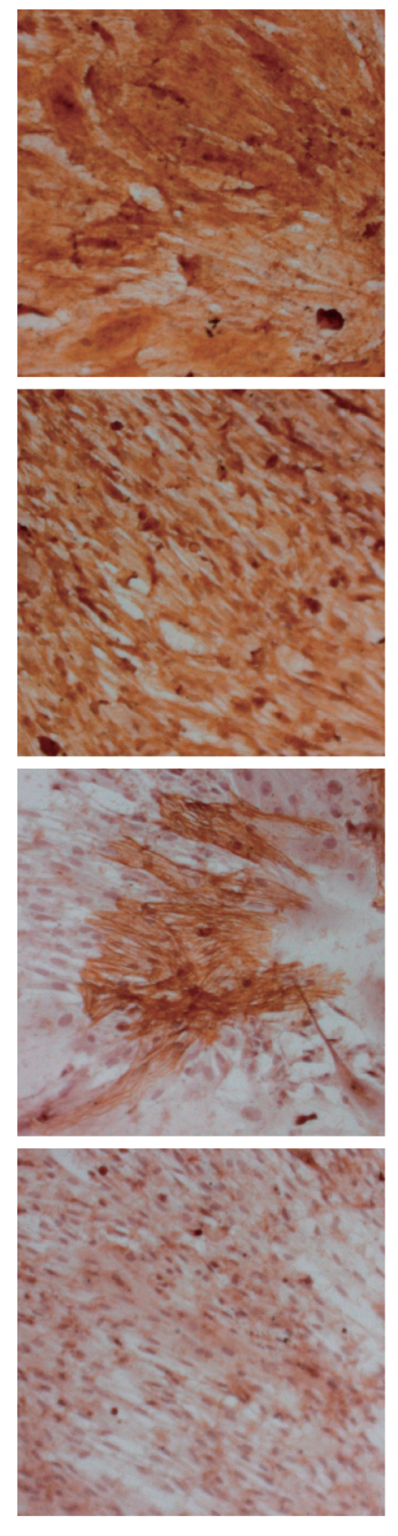

$100 \mu \mathrm{m}$

Fig. 2. The Expression of Cytoskeletal Filaments in Preparations of Cultured Human Fetal Membrane Cells

Confluent monolayers of cultured amnion epithelial, amnion mesenchymal and chorion trophoblast cells on cover slips were obtained. Cytoskeletal filaments, such as cytokeratin 7 , vimentin and $\alpha$-smooth muscle actin, in preparations of cultured cells were detected by immunohistochemistry using respective mouse monoclonal antibodies. Negative control experiments were carried out using non-immunized mouse IgG. The cells were counterstained with hematoxylin solution. The representative microscopic views were shown in panels. Scale bar shows $100 \mu \mathrm{m}$.

for both cytokeratin 7 and vimentin. They have distinct cell shapes, such as epithelial-like and fibroblast-like. Moreover, a small number of myofibroblast-like cells existed in all three cultures. These results are summarized in Table 2.

Cytopathic Effect of Influenza Virus on Cultured Amnion Epithelial, Amnion Mesenchymal and Chorion Trophoblast Cells Rounded and detached cells were observed in cultured chorion trophoblast, not amnion epithelial, cells at $48 \mathrm{~h}$ after influenza virus infection (Fig. 3), corresponding with our previous observations. ${ }^{12)}$ Rounded and detached cells were observed in also amnion mesenchymal cells. The cytopathic effect is characteristic for influenza virus infection.

Induction of Pro-MMP-9 Production and Pro-MMP-2
Cleavage by Influenza Virus Infection Figure 4 presents the results of the gelatin zymography that was performed to determine the gelatinolytic activity of the culture supernatants. At $24-48 \mathrm{~h}$ after the influenza infection, there were significant increases in the activities of pro-MMP-9 $(92 \mathrm{kDa})$ in the culture supernatants of the amnion epithelial, amnion mesenchymal and chorion trophoblast cells, as compared to both the $0-24 \mathrm{~h}$ period and to the mock infection. These results suggest that the virus infection caused an increase in the pro-MMP-9 production in the amnion epithelial, amnion mesenchymal and chorion trophoblast cells.

Furthermore, the activities of pro-MMP-2 $(72 \mathrm{kDa})$ in culture supernatants of chorion trophoblast cells were much 
Table 2. Expression of Cytoskeletal Filaments in Preparations of Cultured Cells

\begin{tabular}{|c|c|c|c|c|}
\hline Preparations & Cell shapes & Cytokeratin 7 & Vimentin & $\alpha$-Smooth muscle actin \\
\hline \multirow[t]{3}{*}{ Cultured amnion epithelial cells } & Epithelial-like & ++ & + & - \\
\hline & Fibroblast-like & ++ & ++ & n.e. \\
\hline & Myofibroblast-like & - & - & ++ \\
\hline \multirow[t]{3}{*}{ Cultured amnion mesenchymal cells } & Epithelial-like & + & + & - \\
\hline & Fibroblast-like & ++ & ++ & n.e. \\
\hline & Myofibroblast-like & - & - & ++ \\
\hline \multirow[t]{2}{*}{ Cultured chorion trophoblast cells } & Fibroblast-like & ++ & ++ & - \\
\hline & Myofibroblast-like & - & - & ++ \\
\hline
\end{tabular}

+, weakly positive; ++ , strongly positive; - , negative; n.e., not estimated.

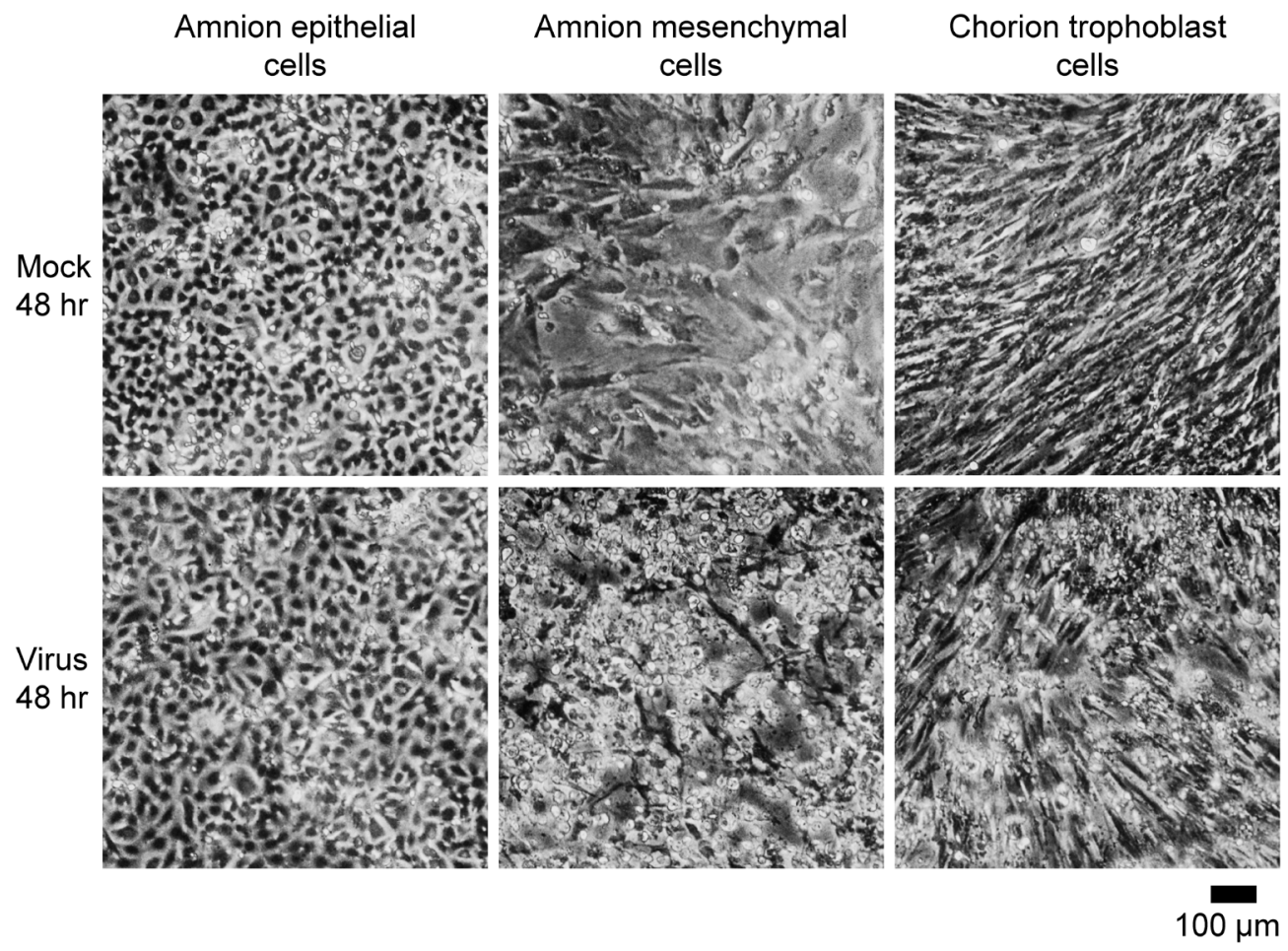

Fig. 3. The Cytopathic Effect of Influenza Virus on Amnion Epithelial, Amnion Mesenchymal and Chorion Trophoblast Cells

After mock (upper panels) and influenza virus infection (lower panels), cultured amnion epithelial, amnion mesenchymal and chorion trophoblast cells were incubated for $48 \mathrm{~h}$. Cells were observed under a microscope. The representative phase contrast views were shown in panels. Scale bar shows $100 \mu$ m.

greater than those of amnion epithelial and amnion mesenchymal cells. The activities of pro-MMP-2 in three types of cells were slightly decreased during the period of $24-48 \mathrm{~h}$ after the virus infection. The activities of an intermediate form of MMP-2 $(68 \mathrm{kDa})$ resulting from cleavage was observed in culture supernatants of chorion trophoblast cells, which significantly increased to 1.4 times during the period of $24-48 \mathrm{~h}$ after the virus infection as compared to that of mock infection or 1.7 times as compared to that of $0-24 \mathrm{~h}$ after the virus infection. However, in amnion epithelial and amnion mesenchymal cells, the intermediate form of MMP-2 was not observed. These results suggested that chorion trophoblast cells produced a large amount of pro-MMP-2 than amnion epithelial and amnion mesenchymal cells, the cleavage of which was enhanced by the virus infection. In negative control experiments, no gelatinolytic activity was observed in the presence of $10 \mathrm{~mm}$ ethylenediaminetetraacetic acid disodium salt during washing and incubating gels (data not shown).

Induction of Gene Expression for MMP-9, but Not
MMP-2, by Influenza Virus Infection During the $0-24 \mathrm{~h}$ period after the influenza virus infection, Western blot analysis (Fig. 5a) of the culture supernatants of the amnion epithelial, amnion mesenchymal and chorion trophoblast cells revealed there were increased levels of pro-MMP-9 protein, which further increased during the $24-48 \mathrm{~h}$ period. Chorion trophoblast cells produced a large amount of pro-MMP-2 protein than amnion epithelial and amnion mesenchymal cells. The active intermediate form of MMP-2 protein increased $2.13 \pm 0.11$ times (the mean and standard deviation, ranging from 2.01 to $2.22, n=3$ ) during the period of $24-48 \mathrm{~h}$ after the virus infection as compared to that of mock infection. The levels of MMP-2 and MMP-9 gelatinolytic activities correlated closely with their protein levels (Fig. 6). A correlation coefficient between them was calculated as $0.871(n=24)$.

At $48 \mathrm{~h}$ after the virus infection, RT-PCR analysis (Fig. 5b) revealed that there were increased levels of the MMP-9 mRNA expression in all of the cultured amnion epithelial, amnion mesenchymal and chorion trophoblast cells, as compared to the 
(a)

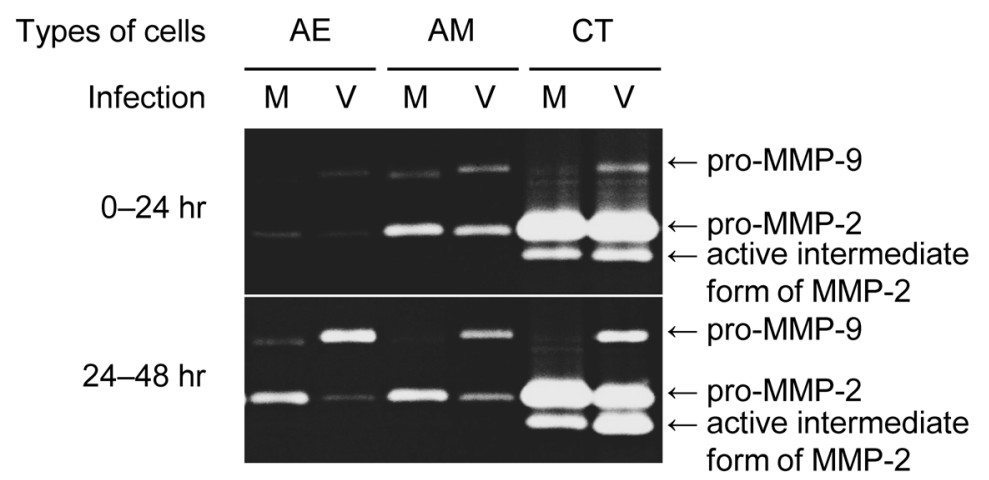

(b)

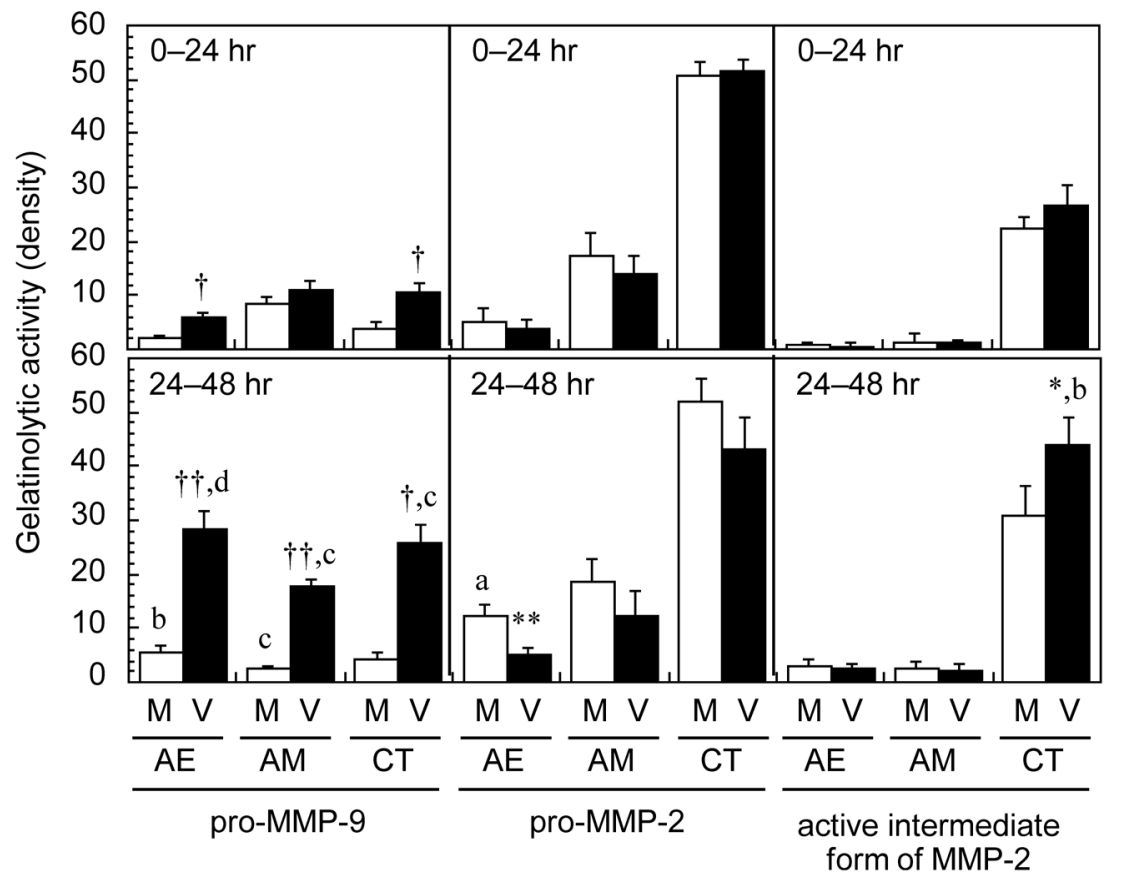

Fig. 4. The Induction of Pro-MMP-9 Production and Pro-MMP-2 Cleavage by Influenza Virus Infection

After mock (M) and influenza virus (V) infection, cultured amnion epithelial (AE), amnion mesenchymal (AM) and chorion trophoblast (CT) cells were incubated with macrophage serum-free medium until $48 \mathrm{~h}$. The medium was changed at $24 \mathrm{~h}$. An aliquot $(5 \mu \mathrm{L})$ of the culture supernatants during the periods of $0-24 \mathrm{~h}$ and $24-48 \mathrm{~h}$ was analyzed by gelatin zymography. The analysis by gelatin zymography was repeated three times. The representative gel images are shown in panel (a). The gelatinolytic activities of pro-MMP-9, pro-MMP-2 and cleaved from of MMP-2 were analyzed by NIH image and shown as densities in panel (b). Open and shaded columns show mock and virus infections, respectively. Data are shown as means and standard deviations. Statistical analysis using the Student $t$-test $(n=3)$ shows significant differences in the activities between mock and virus infections ( $* p<0.05 ; * *<<0.01 ; \dagger p<0.005 ; \dagger \uparrow p<0.001)$ and between the periods of $0-24 \mathrm{~h}$ and $24-48 \mathrm{~h}(\mathrm{a}, p<0.05$; b, $p<0.01$; $\mathrm{c}$ $p<0.005 ; \mathrm{d}, p<0.001)$.

mock infection. In addition, the chorion trophoblast cells exhibited higher levels of MMP-2 mRNA expression versus that seen for the amnion epithelial and amnion mesenchymal cells. After the virus infection, there was also a slight decrease in the levels of the mRNA expression for MMP-2 and MT1-MMP in both the amnion epithelial and mesenchymal cells, but not in the chorion trophoblast cells. There were no changes noted after the virus infection with regard to the levels of the mRNA expression of TIMP-1 and TIMP-2 in these three types of cells. In all of the samples, constant levels were observed for the PCR products for the housekeeping genes, such as $\beta$-actin and G3PDH. Thus, these results suggest that at $48 \mathrm{~h}$ after the influenza virus infection, there was an induction of the expression of MMP-9 mRNA in all of the amnion epithelial, amnion mesenchymal and chorion trophoblast cells.

\section{DISCUSSION}

It has been widely accepted that cytokeratin is one of markers for epithelial cell, and vimentin and $\alpha$-smooth muscle actin are markers for mesenchymal cell. ${ }^{37)}$ Co-expression of both epithelial and mesenchymal markers defines an intermediate phenotype of epithelial to mesenchymal transition (EMT). ${ }^{37}$ Our results demonstrated that cultured amnion epithelial and mesenchymal cells consisted of a large number of epithelial cells and a small number of fibroblast cells, both of which possessed epithelial and mesenchymal phenotypes; cultured chorion trophoblast cells consisted of a large number of fibroblast cells with epithelial and mesenchymal phenotypes. Additionally, a small number of myofibroblast cells existed in all three cultures. Alcaraz et al. have suggested that cultured amnion epithelial cells undergo EMT, resulting in fibroblast and myofibroblast cells. ${ }^{38)}$ Therefore, it is probable that the ex- 
(a)

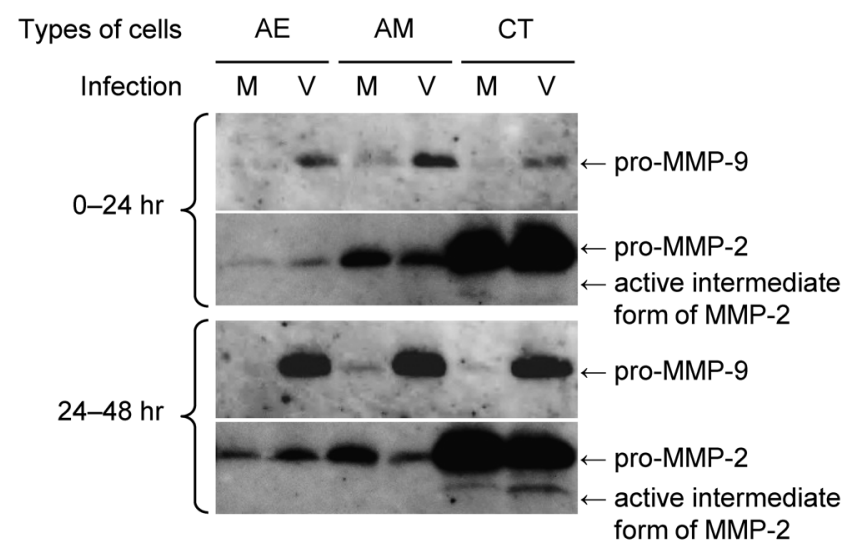

(b)

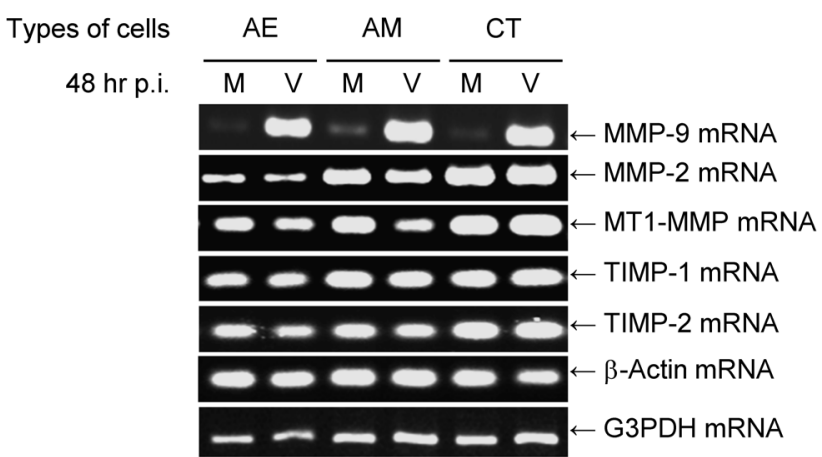

Fig. 5. The Induction of Gene Expression for MMP-9, but Not MMP-2, by Influenza Virus Infection

After mock (M) and influenza virus (V) infection, cultured amnion epithelial (AE), amnion mesenchymal (AM) and chorion trophoblast (CT) cells were incubated with macrophage serum-free medium until $48 \mathrm{~h}$. The medium was changed at $24 \mathrm{~h}$. Panel (a): MMP-9 and MMP-2 proteins in culture supernatants during the periods of $0-24 \mathrm{~h}$ and $24-48 \mathrm{~h}$ were detected by Western blotting, which was repeated three times. The representative images are shown in panels. Panel (b): The expression of MMP-9, MMP-2, MT1-MMP, TIMP-1, TIMP-2, $\beta$-actin and G3PDH mRNAs in the cells at $48 \mathrm{~h}$ post infection (p.i.) were analyzed by RT-PCR. The PCR products were resolved on agarose gels and stained with ethidium bromide. The gel images are shown in panels.

pression showing mixed phenotypes of cells may result from an EMT in not only amnion epithelial cell culture but also amnion mesenchymal and chorion trophoblast cell cultures.

We have previously demonstrated that chorion trophoblast cells and amnion epithelial cells were infected with influenza virus, and moreover that rounded and detached cells were observed in only cultured chorion trophoblast cells. ${ }^{12,39)}$ Our results also showed that amnion mesenchymal cells as well as chorion trophoblast cells both exhibited degenerated cells. Since the cytopathic effect is a characteristic of an influenza virus infection, it is conceivable that the amnion mesenchymal cells are susceptible to influenza virus infections. In order to precisely determine the types of susceptible cells that might be present in preparations of cultured amnion mesenchymal cells, a further study will need to be undertaken.

Our results demonstrated that inductions of gene expression of MMP-9 after an influenza virus infection occurred in three types of cultured cells, the amnion epithelial, amnion mesenchymal and chorion trophoblast cells. It is capable of being considered that common subpopulations in all cultures produced MMP-9 in response to the virus infection. Furthermore, there was a much greater amount of pro-MMP-2 protein spontaneously produced in cultured chorion trophoblast cells

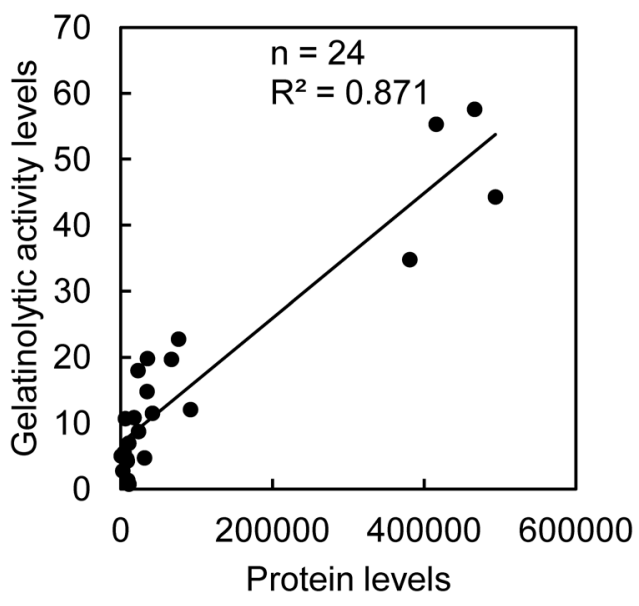

Fig. 6. The Correlation between Gelatinolytic Activity Levels and Protein Levels

Vertical axis expresses the levels of MMP-2 and MMP-9 gelatinolytic activities. Horizontal axis expresses the levels of MMP-2 and MMP-9 proteins.

versus the cultured amnion epithelial and amnion mesenchymal cells, and the virus infection enhanced cleavage of the pro-MMP-2 into an active intermediate form. Previous studies, using non-stimulated amniochorion tissues obtained before the onset of labor, have demonstrated that there was only weak detection of MMP-9 and MMP-2 proteins in the amnion epithelial cells, the amnion mesenchymal cells and the chorion trophoblast cells. However, after stimulations with bacterial toxin and lipopolysaccharide (LPS) in vitro, these proteins were strongly detected in all three types of these cells. ${ }^{40)}$ The secretion of pro-MMP-9 and pro-MMP-2 from isolated amniochorion tissues was increased after the exposure to Escherichia coli. ${ }^{41)}$ The cleavage of pro-MMP-2 into an active intermediate form in isolated amniochorion tissues was observed after the stimulation with LPS $^{40}$ and the exposure to Escherichia coli $^{41)}$ Contrary, it has been published that cytomegalovirus infection reduced the gene expression of MMP-2 and MMP-9 in organ cultured human villous tissues. ${ }^{42)}$ However, in our knowledge, there is no literature demonstrating that virus infection induces the gene expression of MMPs in human gestational tissues. Therefore, the present study demonstrated for the first time that influenza virus infection induced the gene expression of MMP-9 in cultured human fetal membrane cells, such as amnion epithelial, amnion mesenchymal and chorion trophoblast cells, and the cleavage of pro-MMP-2 into an active intermediate form in chorion trophoblast cells as similar to either bacterial exposure or LPS stimulation.

A previous study analyzed the extracts of the amnion and chorion tissues separated from the human amniochorion tissues prior to labor, and detected only minimal levels of proMMP-9 activity. However, when the tissues were analyzed after the onset of labor and after delivery, the authors found a remarkable increase in the levels of pro-MMP-9 activity. ${ }^{43}$ ) Higher concentrations of pro-MMP-9 protein in the amniotic fluids were associated with spontaneous rupture of membranes at term. ${ }^{44)}$ Based on these findings, it is now widely accepted that there is an association between labor and the production of pro-MMP-9 in human fetal membranes. Moreover, during the physiological and pathological parturition processes, it is possible that this increased expression of MMP-9 could lead to the degradation of the extracellular matrix of the fetal 
membranes, thereby facilitating their rupture. When the activity of MMP-2 was assayed by measuring the digestion of an MMP-2 specific substrate, the levels of MMP-2 activity in human amniochorion tissues ruptured prematurely before the onset of labor at term were higher than amniochorion tissues obtained by cesarean section at term before the onset of labor or obtained from normal delivery. ${ }^{45)}$ These results have implied that the activation of pro-MMP-2 may be involved in the degradation of extracellular matrix of the fetal membranes associated with PROM at term. Consequently, our results suggest that the induction of MMP-9 gene expression and pro-MMP-2 cleavage in fetal membrane cells by influenza virus infection may be implicated in a part of the etiology of adverse pregnancy outcomes, such as premature delivery, associated with intrauterine infection with the virus.

Many studies have elucidated some intracellular and extracellular regulators for MMP-2 and MMP-9 gene expression in human fetal membrane cells. The inflammatory response is under the control of cAMP content, which is partly regulated by phosphodiesterases. Rolipram, a selective inhibitor of phosphodiesterase 4 (PDE4), blocked the production of MMP-9 in isolated amniochorion tissues stimulated with LPS. ${ }^{46)} 15$-Deoxy- $\Delta^{12,14}$-prostaglandin $\mathrm{J}_{2}$ and troglitazone, natural and synthetic peroxisome proliferator-activated receptor- $\gamma$ (PPAR- $\gamma$ ) ligands, inhibited the production of MMP-9 in isolated amnion tissues. ${ }^{47)}$ TNF- $\alpha$ and IL- $1 \beta$ increased the production of MMP-9 in cultured amnion epithelial cells, which is inhibited by an antioxidant, $\alpha$-lipoic acid. ${ }^{48)}$ Contrary, oncostatin $\mathrm{M}$ reduced the production of MMP-9 in cultured amnion epithelial cells. ${ }^{49)}$ In addition, the anti-human IL-6 receptor monoclonal antibody, tocilizumab, has been reported to block the IL-6-increased secretion of MMP-2 and MMP-9 from cultured amniotic epithelial cells. ${ }^{50)}$ We have previously demonstrated that influenza virus infection induced the secretion of bioactive IL- 6 and TNF- $\alpha$ proteins from cultured chorion trophoblast, but not amnion epithelial cells. ${ }^{14)}$ In other words, the induction of cytokine production by the virus infection is one-sidedly between two cell types. Therefore, it is probable that some common interventions, such as PDE4 and PPAR- $\gamma$ rather than IL- 6 or TNF- $\alpha$, may contribute to the regulation of MMP-9 gene expression by influenza virus infection among three different types of cultured human fetal membrane cells. It has been shown that the inhibition of caspases with ZVAD-fmk blocked the cleavage of pro-MMP-2 into an intermediate form by MT1-MMP. ${ }^{51)}$ In another prior study, we also found that after an influenza virus infection, the executioner of apoptosis, caspase-3, was cleaved into an active form in the cultured chorion trophoblast, but not in the amnion epithelial cells. ${ }^{39)}$ Consequently, we infer that the activation of caspases may be associated with the cleavage of pro-MMP-2 in cultured chorion trophoblast cells undergoing apoptosis after the virus infection. In order to further clarify the association between influenza virus infections in human fetal membrane cells and the intracellular and extracellular regulators of the induction of the MMP-9 gene expression and pro-MMP-2 cleavage, we are now in the process of conducting further experiments.

In conclusion, the present study suggests that influenza virus infection induces the gene expression of MMP-9 and the cleavage of pro-MMP-2 into an active intermediate form in human fetal membrane cells, resulting in weakening of the membranes through extracellular matrix degradation. Therefore, it is possible that the regulation of MMP gene expression in fetal membrane cells by influenza virus infection is implicated in a part of the etiology of adverse pregnancy outcomes, such as premature delivery, associated with intrauterine infection with the virus. Intracellular and extracellular molecules regulating MMP gene expression in the fetal membranes can be pharmacological targets for helping the management of premature delivery associated with intrauterine influenza virus infection.

Acknowledgments Noboru Uchide and Tsugiya $\mathrm{Mu}$ rayama received the specific research fund of Hokuriku University. Noboru Uchide received Grants from the Ministry of Education, Culture, Sports, Science and Technology of Japan, and from the Promotion and Mutual Aid Corporation for Private School of Japan.

Conflict of Interest The authors declare no conflict of interest.

\section{REFERENCES}

1) Lavery JP. Appendages of the placenta. The human placenta (Lavery JP ed.), Aspen Publishers Inc., Maryland, pp. 257-279 (1987).

2) Malak TM, Bell SC. Structural characteristics of term human fetal membranes: a novel zone of extreme morphological alteration within the rupture site. Br. J. Obstet. Gynaecol., 101, 375-386 (1994).

3) Parry S, Strauss JF 3rd. Premature rupture of the fetal membranes. N. Engl. J. Med., 338, 663-670 (1998).

4) Romero R, Espinoza J, Gonçalves LF, Kusanovic JP, Friel LA, Nien JK. Inflammation in preterm and term labour and delivery. Semin. Fetal Neonatal Med., 11, 317-326 (2006).

5) Uchide N, Ohyama K, Bessho T, Takeichi M, Toyoda H. Possible roles of proinflammatory and chemoattractive cytokines produced by human fetal membrane cells in the pathology of adverse pregnancy outcomes associated with influenza virus infection. Mediators Inflamm., 2012, 270670 (2012).

6) Mosby LG, Rasmussen SA, Jamieson DJ. 2009 pandemic influenza A (H1N1) in pregnancy: a systematic review of the literature. Am. J. Obstet. Gynecol., 205, 10-18 (2011).

7) Lieberman RW, Bagdasarian N, Thomas D, Van De Ven C. Seasonal influenza A (H1N1) infection in early pregnancy and second trimester fetal demise. Emerg. Infect. Dis., 17, 107-109 (2011).

8) McGregor JA, Burns JC, Levin MJ, Burlington B, Meiklejohn G. Transplacental passage of influenza A/Bangkok (H3N2) mimicking amniotic fluid infection syndrome. Am. J. Obstet. Gynecol., 149, 856-859 (1984)

9) Mel'nikova VF, Tsinzerling AV, Aksenov OA, Vydumkina SP, Kalinina NA. Involvement of the afterbirth in influenza. Arkh. Patol., 49, 19-25 (1987).

10) Gu J, Xie Z, Gao Z, Liu J, Korteweg C, Ye J, Lau LT, Lu J, Gao Z, Zhang B, McNutt MA, Lu M, Anderson VM, Gong E, Yu AC, Lipkin WI. H5N1 infection of the respiratory tract and beyond: a molecular pathology study. Lancet, 370, 1137-1145 (2007).

11) $\mathrm{Xu} \mathrm{L}$, Bao L, Deng W, Qin C. Highly pathogenic avian influenza H5N1 virus could partly be evacuated by pregnant BALB/c mouse during abortion or preterm delivery. Virol. J., 8, 342 (2011).

12) Uchide N, Ohyama K, Bessho T, Yuan B, Yamakawa T. Apoptosis in cultured human fetal membrane cells infected with influenza virus. Biol. Pharm. Bull., 25, 109-114 (2002).

13) Uchide N, Ohyama K, Yuan B, Sano T, Bessho T, Yamakawa $T$. Differential mRNA expression of inflammatory cytokines in cultured human fetal membrane cells responding to influenza virus 
infection. Biol. Pharm. Bull., 25, 239-243 (2002).

14) Uchide N, Suzuki A, Ohyama K, Bessho T, Toyoda H. Secretion of bioactive interleukin- 6 and tumor necrosis factor- $\alpha$ proteins from primary cultured human fetal membrane chorion cells infected with influenza virus. Placenta, 27, 678-690 (2006).

15) Uchide N, Ohyama K, Bessho T, Toyoda H. Induction of pro-inflammatory cytokine gene expression and apoptosis in human chorion cells of fetal membranes by influenza virus infection: possible implications for maintenance and interruption of pregnancy during infection. Med. Sci. Monit., 11, RA7-RA16 (2005).

16) Menon R, Fortunato SJ. Infection and the role of inflammation in preterm premature rupture of the membranes. Best Pract. Res. Clin. Obstet. Gynaecol., 21, 467-478 (2007).

17) Vadillo-Ortega F, Hernandez A, Gonzalez-Avila G, Bermejo L, Iwata K, Strauss JF 3rd. Increased matrix metalloproteinase activity and reduced tissue inhibitor of metalloproteinases-1 levels in amniotic fluids from pregnancies complicated by premature rupture of membranes. Am. J. Obstet. Gynecol., 174, 1371-1376 (1996).

18) Fortunato SJ, Menon R, Lombardi SJ. Collagenolytic enzymes (gelatinases) and their inhibitors in human amniochorionic membrane. Am. J. Obstet. Gynecol., 177, 731-741 (1997).

19) Menon R, Fortunato SJ. The role of matrix degrading enzymes and apoptosis in rupture of membranes. J. Soc. Gynecol. Investig., 11, 427-437 (2004).

20) Geng J, Huang C, Jiang S. Roles and regulation of the matrix metalloproteinase system in parturition. Mol. Reprod. Dev., 83, 276-286 (2016).

21) Weiss A, Goldman S, Shalev E. The matrix metalloproteinases (MMPS) in the decidua and fetal membranes. Front. Biosci., 12, 649-659 (2007).

22) Fortunato SJ, Menon R. IL-1 $\beta$ is a better inducer of apoptosis in human fetal membranes than IL-6. Placenta, 24, 922-928 (2003).

23) Menon R, Lombardi SJ, Fortunato SJ. TNF- $\alpha$ promotes caspase activation and apoptosis in human fetal membranes. J. Assist. Reprod. Genet., 19, 201-204 (2002).

24) Kumar D, Fung W, Moore RM, Pandey V, Fox J, Stetzer B, Mansour JM, Mercer BM, Redline RW, Moore JJ. Proinflammatory cytokines found in amniotic fluid induce collagen remodeling, apoptosis, and biophysical weakening of cultured human fetal membranes. Biol. Reprod., 74, 29-34 (2006).

25) Yeo SJ, Kim SJ, Kim JH, Lee HJ, Kook YH. Influenza A virus infection modulates the expression of type IV collagenase in epithelial cells. Arch. Virol., 144, 1361-1370 (1999).

26) Wang S, Quang Le T, Chida J, Cisse Y, Yano M, Kido H. Mechanisms of matrix metalloproteinase-9 upregulation and tissue destruction in various organs in influenza A virus infection. J. Med. Invest., 57, 26-34 (2010)

27) Shapiro S, Khodalev O, Bitterman H, Auslender R, Lahat N. Different activation forms of MMP-2 oppositely affect the fate of endotheial cells. Am. J. Physiol. Cell Physiol., 298, C942-C951 (2010).

28) Sun K, Qu X, Gao L, Myatt L. Dexamethasone fails to inhibit the induction of cytosolic phospholipase $A_{2}$ expression by interleukin- $1 \beta$ in cultured primary human amnion fibroblasts. Placenta, 27, 164-170 (2006).

29) Steel JH, O'donoghue K, Kennea NL, Sullivan MH, Edwards AD. Maternal origin of inflammatory leukocytes in preterm fetal membranes, shown by fluorescence in situ hybridisation. Placenta, 26, 672-677 (2005).

30) Gibb W, Sun M. Cellular specificity of interleukin- $1 \beta$-stimulated expression of type-2 prostaglandin $\mathrm{H}$ synthase in human amnion cell cultures. Biol. Reprod., 59, 1139-1142 (1998).

31) McParland PC, Taylor DJ, Bell SC. Myofibroblast differentiation in the connective tissues of the amnion and chorion of term human fetal membranes-implications for fetal membrane rupture and labour. Placenta, 21, 44-53 (2000).

32) Kim SS, Romero R, Kim JS, Abbas A, Espinoza J, Kusanovic JP,
Hassan S, Yoon BH, Kim CJ. Coexpression of myofibroblast and macrophage markers: novel evidence for an in vivo plasticity of chorioamniotic mesodermal cells of the human placenta. Lab. Invest., 88, 365-374 (2008)

33) Sato T, Iwai M, Sakai T, Sato H, Seiki M, Mori Y, Ito A. Enhancement of membrane-type 1-matrix metalloproteinase (MT1-MMP) production and sequential activation of progelatinase A on human squamous carcinoma cells co-cultured with human dermal fibroblasts. Br. J. Cancer, 80, 1137-1143 (1999).

34) Ogawa K, Chen F, Kuang C, Chen Y. Suppression of matrix metalloproteinase- 9 transcription by transforming growth factor- $\beta$ is mediated by a nuclear factor- $\kappa$ B site. Biochem. J., 381, 413-422 (2004). 35) Yu H, Pan C, Zhao S, Wang Z, Zhang H, Wu W. Resveratrol inhibits tumor necrosis factor- $\alpha$-mediated matrix metalloproteinase- 9 expression and invasion of human hepatocellular carcinoma cells. Biomed. Pharmacother., 62, 366-372 (2008).

36) Figueira RC, Gomes LR, Neto JS, Silva FC, Silva ID, Sogayar MC. Correlation between MMPs and their inhibitors in breast cancer tumor tissue specimens and in cell lines with different metastatic potential. BMC Cancer, 9, 20 (2009).

37) Kalluri R, Weinberg RA. The basics of epithelial-mesenchymal transition. J. Clin. Invest., 119, 1420-1428 (2009).

38) Alcaraz A, Mrowiec A, Insausti CL, García-Vizcaíno EM, RuizCanada C, López-Martínez MC, Moraleda JM, Nicolás FJ. Autocrine TGF- $\beta$ induces epithelial to mesenchymal transition in human amniotic epithelial cells. Cell Transplant., 22, 1351-1367 (2013).

39) Uchide N, Ohyama K, Bessho T, Toyoda H. Lactate dehydrogenase leakage as a marker for apoptotic cell degradation induced by influenza virus infection in human fetal membrane cells. Intervirology, 52, 164-173 (2009).

40) Garcia-Lopez G, Vadillo-Ortega F, Merchant-Larios H, MaidaClaros R, Osorio M, Soriano-Becerril D, Flores-Herrera H, BeltranMontoya J, Garfias-Becerra Y, Zaga-Clavellina V. Evidence of in vitro differential secretion of 72 and $92 \mathrm{kDa}$ type IV collagenases after selective exposure to lipopolysaccharide in human fetal membranes. Mol. Hum. Reprod., 13, 409-418 (2007).

41) Zaga-Clavellina V, Garcia-Lopez G, Flores-Pliego A, MerchantLarios H, Vadillo-Ortega F. In vitro secretion and activity profiles of matrix metalloproteinases, MMP-9 and MMP-2, in human term extra-placental membranes after exposure to Escherichia coli. Reprod. Biol. Endocrinol., 9, 13 (2011).

42) Tao L, Suhua C, Juanjuan C, Zongzhi Y, Juan X, Dandan Z. In vitro study on human cytomegalovirus affecting early pregnancy villous EVT's invasion function. Virol. J., 8, 114 (2011).

43) Vadillo-Ortega F, González-Avila G, Furth EE, Lei H, Muschel RJ, Stetler-Stevenson WG, Strauss JF 3rd. 92-kd type IV collagenase (matrix metalloproteinase-9) activity in human amniochorion increases with labor. Am. J. Pathol., 146, 148-156 (1995).

44) Athayde N, Edwin SS, Romero R, Gomez R, Maymon E, Pacora $\mathrm{P}$, Menon R. A role for matrix metalloproteinase-9 in spontaneous rupture of the fetal membranes. Am. J. Obstet. Gynecol., 179, 1248-1253 (1998).

45) Ota A, Yonemoto H, Someya A, Itoh S, Kinoshita K, Nagaoka I. Changes in matrix metalloproteinase 2 activities in amniochorions during premature rupture of membranes. J. Soc. Gynecol. Investig., 13, 592-597 (2006)

46) Oger S, Méhats C, Dallot E, Cabrol D, Leroy MJ. Evidence for a role of phosphodiesterase 4 in lipopolysaccharide-stimulated prostaglandin $\mathrm{E}_{2}$ production and matrix metalloproteinase-9 activity in human amniochorionic membranes. J. Immunol., 174, 8082-8089 (2005).

47) Lappas M, Permezel M, Rice GE. 15-Deoxy- $\Delta^{12,14}$-prostaglandin $J_{2}$ and troglitazone regulation of the release of phospholipid metabolites, inflammatory cytokines and proteases from human gestational tissues. Placenta, 27, 1060-1072 (2006).

48) Moore RM, Novak JB, Kumar D, Mansour JM, Mercer BM, Moore 
JJ. Alpha-lipoic acid inhibits tumor necrosis factor-induced remodeling and weakening of human fetal membranes. Biol. Reprod., $\mathbf{8 0}$, 781-787 (2009)

49) Izumi-Yoneda N, Toda A, Okabe M, Koike C, Takashima S, Yoshida T, Konishi I, Saito S, Nikaido T. Alpha 1 antitrypsin activity is decreased in human amnion in premature rupture of the fetal membranes. Mol. Hum. Reprod., 15, 49-57 (2009).

50) Mano Y, Shibata K, Sumigama S, Hayakawa H, Ino K, Yamamoto
E, Kajiyama H, Nawa A, Kikkawa F. Tocilizumab inhibits interleukin-6-mediated matrix metalloproteinase-2 and -9 secretions from human amnion cells in preterm premature rupture of membranes. Gynecol. Obstet. Invest., 68, 145-153 (2009).

51) Levkau B, Kenagy RD, Karsan A, Weitkamp B, Clowes AW, Ross $\mathrm{R}$, Raines EW. Activation of metalloproteinases and their association with integrins: an auxiliary apoptotic pathway in human endothelial cells. Cell Death Differ., 9, 1360-1367 (2002). 